\title{
Cosmic-Ray Heavy-Nucleus Enders at Various Atmospheric Depths.
}

\author{
K. FUKUI \\ Air Force Cambridge Research Laboratories - Bedford, Mass. \\ Y. K. LIM \\ Emmanuel College - Boston, Mass. \\ P. S. YOUNG \\ Mississippi State University - State College, Miss. \\ (Nuovo Cimento, 61 B, $210(1969)$ )
}

Due to an error in the manuscript, the name of the third co-author of this paper has been misprinted; the correct name is given above.

\section{Inner Bremsstrahlung Spectrum of ${ }^{55} \mathrm{Fe}$ with a $\mathrm{Ge}(\mathrm{Li})$ Detector.}

Y. KABASAKAL and M. K. RAMASWAMY

Department of Physics, Fordham University - Bronx, N. Y.

(Nuovo Cimento, $61 \mathrm{~B}, 220$ (1969))

Dr. D. BERENYI has kindly brought to our attention his scintillation counter value of $(218 \pm 4) \mathrm{keV}$ for the end-point of the IB spectrum; see: Phys. Lett., 18, 293 (1965). 